\title{
Rapid Synaptic Plasticity of Glutamatergic Synapses on Dopamine Neurons in the Ventral Tegmental Area in Response to Acute Amphetamine Injection
}

\author{
Lavina J Faleiro ${ }^{1,3}$, Susan Jones ${ }^{2}$ and Julie A Kauer*, \\ 'Department of Molecular Pharmacology, Physiology and Biotechnology, Brown University, Providence, RI, USA; ${ }^{2}$ Department of Anatomy, \\ University of Cambridge, Downing Street, Cambridge, UK
}

\begin{abstract}
Drugs of abuse activate the reward circuitry of the mesocorticolimbic system, and it has been hypothesized that drug exposure triggers synaptic plasticity of glutamatergic synapses onto dopamine (DA) neurons of the ventral tegmental area. Here, we show that just a $2 \mathrm{~h}$ in vivo exposure to amphetamine is sufficient to potentiate these synapses, measured as an increase in the synaptic AMPAR/NMDAR ratio. We tested the prediction that an increase in GluRI-containing AMPA receptors would result in an increase in GluRI homomeric receptors at synapses, but were unable to observe any evidence of the predicted rectification in DA neurons from animals treated with amphetamine. We also examined the possibility of increased AMPA receptor insertion in the membrane, but did not detect a significant increase in biotinylated surface GluRI. We conclude that amphetamine induces rapid changes in synaptic AMPAR/NMDAR ratios, suggesting that potentiation of glutamatergic synapses is a relatively early event in the series of neuroadaptations in response to drugs of abuse.

Neuropsychopharmacology (2004) 29, 2 II5-2125, advance online publication, 19 May 2004; doi: I 0. I 038/sj.npp. I 300495
\end{abstract}

Keywords: synaptic plasticity; sensitization; psychostimulant; dopaminergic; AMPAR/NMDAR ratio; LTP

\section{INTRODUCTION}

The mesocorticolimbic system is activated both by naturally rewarding stimuli and by drugs of abuse. Addictive behaviors are thought to result from persistent molecular and cellular neuroadaptations in the mesocorticolimbic circuit that follow exposure to drugs of abuse. The mesocorticolimbic circuit includes dopamine (DA) neurons in the ventral tegmental area (VTA) that project to the nucleus accumbens (NAcc) and prefrontal cortex (Beckstead, 1979; Christie et al, 1985; Oades and Halliday, 1987; Carr and Sesack, 1996). Nearly all addictive drugs share the ability to cause DA release at nerve terminals in the NAcc (Di Chiara and Imperato, 1988), and this shared property of drugs with different molecular targets may be responsible

\footnotetext{
*Correspondence: Dr JA Kauer, Department of Molecular Pharmacology, Physiology and Biotechnology, Brown University, Providence, RI 029|2, USA, Tel: + | 401863 9803, Fax: + | 40 I 863 1595, E-mail: julie_kauer@brown.edu

${ }^{3}$ Current address: Brookhaven National Laboratory, Medical Department, Building 490, Upton, NY I 1973, USA

Received 2 December 2003; revised 24 March 2004; accepted 9 April 2004

Online publication: 23 April 2004 at http://www.acnp.org/citations/ Npp04230403553/default.pdf
}

for setting into motion maladaptive processes that underlie addiction (Koob, 1992; Nestler, 1992).

Repeated exposure to drugs of abuse in rodents also leads to progressive and long-lasting enhancement of certain behaviors, a process known as behavioral sensitization. The persistent neuroadaptations in mesolimbic circuitry responsible for behavioral sensitization are thought to parallel neuroadaptations that underlie the intensification of drug craving during the development of addiction (Robinson and Berridge, 1993; Self and Nestler, 1998). Thus, considerable effort has been directed at studying the mechanisms responsible for behavioral sensitization. Local effects of drugs of abuse on VTA neurons appear to be necessary and sufficient to trigger sensitization, because repeated local microinjections of amphetamine or morphine into the VTA elicit behavioral sensitization (Kalivas and Duffy, 1987; Kalivas and Weber, 1988; Druhan et al, 1993; Vezina, 1993; Cador et al, 1995) and microinjections of specific DA or glutamate receptor antagonists into the VTA prevent sensitization (Vezina and Stewart, 1989; Kalivas and Alesdatter, 1993; Bjijou et al, 1996; Kim and Vezina, 1998; Cador et al, 1999; Vezina and Queen, 2000). Several lines of evidence support the idea that synaptic plasticity at glutamate synapses in the VTA plays a key role in triggering sensitization and other neuroadaptations that may contribute to the development of addiction (Schenk and Snow, 
1994; White, 1996; Carlezon et al, 1997; Ungless et al, 2001; Hyman and Malenka, 2001; Kauer, 2004). Most recently it has been demonstrated that the glutamate receptor complement (AMPAR/NMDAR ratio) at excitatory synapses onto VTA DA neurons is altered $24 \mathrm{~h}$ after exposure to several distinct drugs of abuse, but not by centrally acting drugs that are not addictive (Ungless et al, 2001; Saal et al, 2003). Together, the data indicate that $24 \mathrm{~h}$ after a single exposure to an addictive drug, alterations in excitatory synapses can be observed that are consistent with long-term potentiation. However, the question as to how rapidly drugs of abuse alter synaptic function remains unanswered.

Here, we examined in greater detail the development of behavioral sensitization to amphetamine in young rats and the accompanying changes in glutamatergic synapses. We found that a single dose of amphetamine not only induced sensitization but also was sufficient to increase AMPAR/ NMDAR ratios in drug-treated animals. Biochemical analyses of the GluR1 subunit of the AMPA receptor did not reveal differences in surface expression in VTA neurons between amphetamine-treated and saline controls. Moreover, we found no differences in rectification of currentvoltage relationships of synaptic AMPA receptors. Intriguingly, a 2-h in vivo exposure to amphetamine is sufficient to induce an increase in AMPAR/NMDAR ratio at glutamatergic synapses onto DA neurons. An in vitro exposure to amphetamine for a similar time period, however, was not sufficient to increase AMPAR/NMDAR ratios significantly.

\section{MATERIALS AND METHODS}

\section{Animals}

Subjects were male and female Sprague-Dawley rats between 11-18 days of age. Rats were housed in a colony room for a minimum of 6 days before initiating behavioral experiments. The colony room is maintained at $72{ }^{\circ} \mathrm{F}$, lightdark cycle: 0700-1900 lights on.

\section{Behavioral Sensitization Assay-5-Day Treatments Followed by Withdrawal and Amphetamine Challenge}

Pretreatment. At 3 days prior to the start of injections, individual rats (P8) were removed from their home cages, brought up to the room housing the sensitization boxes, handled for $15-30 \mathrm{~min}$, and then returned to their home cages.

\section{Treatment}

Rats (P11) were weighed and then placed in the sensitization chambers for $20-30 \mathrm{~min}$ prior to receiving s.c. injections. Rats were administered either amphetamine $(2.5 \mathrm{mg} / \mathrm{kg})$ or a comparable volume of saline on days 1-5 and were returned to the sensitization chambers. Horizontal ambulation was measured for $40 \mathrm{~min}$ after each injection (San Diego Instruments, Photobeam Activity System). Animals were returned to their home cage $1-2 \mathrm{~h}$ after receiving their injections. For the amphetamine challenge, rats were removed from the animal colony on days 2,4 , and 8 after cessation of drug administration, and weighed and then placed in the sensitization boxes for 20-30 min.
Following this time, they were administered amphetamine $(2.5 \mathrm{mg} / \mathrm{kg})$ as an i.p. injection. Following the injections, rats were returned to the sensitization boxes for up to $60 \mathrm{~min}$ to monitor horizontal ambulation. Stereotyped sniffing was assessed $30 \mathrm{~min}$ after the challenge injection by quantifying the time the animal was engaged in sniffing behavior during $60 \mathrm{~s}$ intervals. Behavioral responses to repeated saline or amphetamine injections and responses to subsequent amphetamine challenge following withdrawal were compared using an unpaired, two-tailed Student's $t$-test. For this and all other experiments, $p$-values $\leqslant 0.05$ were considered significant and values are reported as means \pm SEM.

\section{Behavioral Sensitization Assay-Single Amphetamine Administration Followed by Amphetamine Challenge}

Pretreatment. At 3 days prior to the start of injections, individual rats (P12) were removed from their home cages, brought up to the room housing the sensitization boxes, handled for $15-30 \mathrm{~min}$, and then returned to their home cages.

Treatment. Rats (P15) were weighed and then placed in the sensitization chambers for 20-30 min prior to receiving i.p. injections. Rats were administered either amphetamine $(2.5 \mathrm{mg} / \mathrm{kg}$, i.p.) or a comparable volume of saline on day 1 and were returned to the sensitization chambers for $40 \mathrm{~min}$ following the injections to monitor horizontal ambulation, after which they were returned to their home cage. The next day, rats were removed from the animal colony, and weighed and then placed in the sensitization boxes for 20$30 \mathrm{~min}$. They were all administered the amphetamine challenge $(2.5 \mathrm{mg} / \mathrm{kg})$ as an i.p. injection. Following the injections, rats were returned to the sensitization boxes and horizontal ambulation was measured for $40 \mathrm{~min}$ after each injection. Behavioral responses to saline or amphetamine injections and responses to subsequent amphetamine challenge were compared using an unpaired, two-tailed $t$ test.

\section{Single In Vivo Amphetamine Administration for 24 h Physiology Experiments}

Treatment. Rats (P15-18) were removed from the animal colony, and weighed and then were administered either amphetamine $(2.5 \mathrm{mg} / \mathrm{kg}$, i.p.) or a comparable volume of saline on day 1 and rats were then returned to their home cages. The next day, $24 \mathrm{~h}$ after injections, rats were killed and brain slices were prepared as described below. All injections were administered between 0900 and 1100 .

\section{Single In Vivo Amphetamine Administration for $2 \mathrm{~h}$ Physiology Experiments}

Treatment. Rats (P15-18) were removed from the animal colony, and weighed and then placed in the sensitization chambers for 20-30 min prior to receiving i.p. injections. Rats were administered either amphetamine $(2.5 \mathrm{mg} / \mathrm{kg})$ or a comparable volume of saline and were returned to the sensitization chambers for an hour following the injections. The rats remained in the sensitization boxes for an additional hour, after which they were killed. All injections 
were administered between 0900 and 1100. Behavioral responses to saline or amphetamine injections were compared using an unpaired, two-tailed $t$-test.

Some animals did not behave as expected in response to the injections, perhaps as a result of factors not related to the drug treatment itself (eg stress response to injections). Therefore, control animals (6/25) that received a saline injection but showed greater than 120 ambulation counts/ hour were not studied further using electrophysiological analyses; similarly, those animals (7/25) that did not display an ambulatory response greater than 120 counts/h in response to amphetamine injections were also not studied further.

\section{Preparation of Brain Slices}

Sprague-Dawley rats (P15-18) were anesthetized using halothane and were quickly decapitated. The brain was rapidly removed into ice-cold artificial cerebrospinal fluid (Sucrose ACSF) containing (in mM): $119 \mathrm{NaCl}, 26 \mathrm{NaHCO}_{3}$, $2.5 \mathrm{KCl}, 1 \mathrm{NaH}_{2} \mathrm{PO}_{4}, 0.5 \mathrm{CaCl}_{2}, 12 \mathrm{MgSO}_{4}, 10$ glucose, 75 sucrose) continually gassed with $95 \% \mathrm{O}_{2} / 5 \% \mathrm{CO}_{2}$. Horizontal midbrain slices $(250 \mu \mathrm{m}$ thick) containing VTA were cut using a Leica 1000 vibratome and transferred into a submersion storage chamber at $27^{\circ} \mathrm{C}$ containing sucrose modified ACSF gassed with $95 \% \mathrm{O}_{2} / 5 \% \mathrm{CO}_{2}$.

\section{Intracellular Recordings from DA Neurons}

Slices were transferred into a recording chamber between 1 and $6 \mathrm{~h}$ after preparation. The slice was submerged in warm ACSF $\left(28-30^{\circ} \mathrm{C}\right)$ containing $(\mathrm{mM}): 119 \mathrm{NaCl}, 26 \mathrm{NaHCO}_{3}$, $2.5 \mathrm{KCl}, 1 \mathrm{NaH}_{2} \mathrm{PO}_{4}, 2.5 \mathrm{CaCl}_{2}, 1.3 \mathrm{MgSO}_{4}, 10$ glucose. Picrotoxin $(0.1 \mathrm{mM})$ was included to block $\mathrm{GABA}_{\mathrm{A}}$ receptors to isolate excitatory synaptic transmission. For wholecell patch-clamp recordings, individual cells in the VTA were visualized on a monitor using an Olympus BX50WI with a $\times 40$ water-immersion objective with differential interference contrast, IR filter, and a CCD camera. Patch pipettes were filled with cesium gluconate-based internal solution containing $(\mathrm{mM})$ : Cs-gluconate $117, \mathrm{NaCl} 2.8$, HEPES 20, $\mathrm{MgCl}_{2}$ 5, EGTA 5, $\mathrm{CaCl}_{2}$ 0.5, ATP-Na ${ }^{+}$2, GTP$\mathrm{Na}^{+}$1.7. The cell input resistance and series resistance were monitored throughout the experiment; experiments were discarded if these values changed by more than $10 \%$ during the experiment. DA neurons were identified by the presence of the distinctive current sag response to hyperpolarizing current mediated by the $I_{\mathrm{H}}$ current. Cells were held at $-55 \mathrm{mV}$ and hyperpolarizing current steps to $-105 \mathrm{mV}$ were delivered. The 'sag' was measured as peak current minus current remaining at the end of a $700 \mathrm{~ms}$ step from -55 to $-105 \mathrm{mV}$. Cells with a sag response less then $25 \mathrm{pA}$ at $-105 \mathrm{mV}$ were considered likely to be nondopaminergic and were excluded from further study.

A bipolar stainless-steel stimulating electrode was placed rostral to the recording site in the VTA to stimulate glutamatergic afferents at $0.1 \mathrm{~Hz}(100 \mu \mathrm{s}$ pulse, $5-50 \mu \mathrm{A})$. Cells were initially held at $-60 \mathrm{mV}$ for 5-10 min and were slowly depolarized to $+40 \mathrm{mV}$. After recording at least $10 \mathrm{~min}$ of stable EPSCs, D-APV $(50 \mu \mathrm{M})$ was added to the bath to block NMDA currents. AMPAR/NMDAR ratios were calculated by measuring the average peak EPSC at $+40 \mathrm{mV}$
(30 EPSCs recorded over $5 \mathrm{~min}$ ) before and $10 \mathrm{~min}$ after application of APV. The NMDAR-mediated EPSP amplitude was calculated by subtracting the AMPAR amplitude (peak current in APV) from the total current without APV. Recordings were made from a single cell from each treated animals. Slices from saline-treated animals were interleaved with slices from amphetamine-treated littermates. AMPAR/ NMDAR ratios for control and amphetamine-treated groups were compared using an unpaired, two-tailed Student's $t$-test.

Data for the rectification analysis were collected from cells bathed in ACSF + picrotoxin + D-APV and held at voltages between -70 and $+60 \mathrm{mV}$. Values at $\pm 40 \mathrm{mV}$ from the EPSC reversal potential $\left(E_{\text {rev }+40} / E_{\text {rev }-40}\right)$ were used to normalize for variations in space clamp. The apparent reversal potentials $\left(E_{\text {rev }}\right)$ of individual DA neurons varied between +5 to $+15 \mathrm{mV}$; there were no differences in the reversal potentials of neurons from saline- and amphetamine-treated rats. Values are not corrected for the liquid junction potential. Recordings were made from a single cell from each treated animals. Slices from salinetreated animals were interleaved with slices from amphetamine-treated littermates. $E_{\text {rev }+40} / E_{\text {rev }-40}$ ratios for control and amphetamine-treated cells were compared using an unpaired, two-tailed Student's $t$-test.

\section{2-h In Vitro Exposure of VTA Slices to Amphetamine}

Brain slices were prepared from naive rats (P15-18) as described above. Slices were incubated in a submersion chamber at $27^{\circ} \mathrm{C}$ containing sucrose modified ACSF saturated with $95 \% \mathrm{O}_{2} / 5 \% \mathrm{CO}_{2}$ for $1 \mathrm{~h}$. Slices were then transferred into a second submersion chamber containing ACSF saturated with $95 \% \quad \mathrm{O}_{2} / 5 \% \quad \mathrm{CO}_{2}$ with or without amphetamine $(1 \mu \mathrm{M})$. At $1 \mathrm{~h}$ after amphetamine/vehicle exposure, a VTA slice was transferred into the recording chamber perfused with warm ACSF \pm amphetamine (28$\left.30^{\circ} \mathrm{C}\right)$; picrotoxin $(0.1 \mathrm{mM})$ was added to the perfusion solution only after whole-cell configuration was attained. AMPAR/NMDAR ratios were obtained as described above. Cells were recorded between 105 and $180 \mathrm{~min}$ after the start of amphetamine or vehicle exposure. Recordings were made from a single cell from each slice. Vehicle-treated slices were interleaved with amphetamine-treated slices taken from the same animals whenever possible. AMPAR/NMDAR ratios for control and amphetamine-treated groups were compared using an unpaired, two-tailed $t$-test.

\section{Biotinylation of Surface Receptors}

These assays essentially followed the protocols reported in Gutlerner et al (2002). Horizontal midbrain slices (three slices per rat) were prepared from rats exposed to a single injection of saline or amphetamine for $24 \mathrm{~h}$. Initial experiments comparing the rate of biotinylation of surface receptors in slices that had recovered in modified ACSF either at $27^{\circ} \mathrm{C}$ or on ice showed a higher rate of biotinylation in slices that were held on ice. Therefore, slices were stored on ice for $1 \mathrm{~h}$ in modified ACSF and then were incubated in ice-cold modified ACSF + biotin $(1 \mathrm{mg} / \mathrm{ml}$; NHS-SS-biotin, Pierce Chemical Company, Rockford, IL) for $20 \mathrm{~min}$ on ice. Slices were rinsed three times with ice-cold modified ACSF 
to wash away excess unbound biotin. The VTA was then dissected away from the remainder of the brain slice under a dissecting scope using approximate boundaries defined in a rat brain atlas (Paxinos and Watson, 1986). All the VTA tissue from one animal was homogenized in $1 \mathrm{ml}$ of modified RIPA buffer $(0.1 \%$ Triton, $0.5 \%$ SDS, $0.5 \%$ deoxycholate, $150 \mathrm{mM} \mathrm{NaCl}, 10 \mathrm{mM} \mathrm{NaPO}_{4}, 2 \mathrm{mM}$ EDTA, $50 \mathrm{mM} \mathrm{NaF}, 10 \mathrm{mM}$ sodium pyrophosphate, $10 \mathrm{mM}$ sodium iodoacetamide, $1 \mathrm{mM}$ orthovanadate, $0.1 \mathrm{mM}$ PMSF, protease inhibitor cocktail III (Calbiochem, San Diego, CA)). Homogenates were incubated on ice for $20 \mathrm{~min}$ and then centrifuged at $14000 \mathrm{~g}$ at $4{ }^{\circ} \mathrm{C}$ for $15 \mathrm{~min}$. Protein concentrations were measured using the BCA protein assay (Pierce Chemical Company). For each set of slices, protein was processed as follows and in triplicate. Protein $(10 \mu \mathrm{g})$ was removed to measure total GluR1, NR1, transferrin (membrane protein control), synapsin (intracellular protein control for biotinylation of internal proteins); for surface protein, $50 \mu \mathrm{g}$ of protein were incubated with $75 \mu \mathrm{l}$ of $50 \%$ Neutravidin Agarose (Pierce Chemical Company) overnight at $4{ }^{\circ} \mathrm{C}$ and bound proteins were resuspended in $30 \mu \mathrm{l}$ of SDS sample buffer and boiled. Quantitative Western blots were performed on both total and biotinylated (surface) proteins using antibodies for GluR1 C-terminus (1:1000; Upstate Biotechnology, Lake Placid, NY), NR1 C-terminus (1:500, Santa Cruz Antibodies, Santa Cruz, CA), transferrin ( $1: 10000$, MAb H68.4; Zymed, San Francisco, CA), and synapsin (1:5000 Chemicon, Temecula, CA). Approximately $8 \%$ of synapsin was biotinylated, indicating that very little intracellular protein contaminates the 'surface' fraction. Immunoreactive bands were visualized by enhanced chemifluorescence (ECLplus; Amersham, Piscataway, NJ) and captured using the Storm Imaging System (Amersham) and quantified using the ImageQuant software (Amersham). Various methods of quantification are provided with the analysis program ImageQuant and were used to quantify each band, including peak area, object average, and local average. None of these quantification methods gave significantly different results for the two treatment groups, and we report values for the surface: total ratio calculated using peak area. The results from saline- $v s$ amphetamine-treated rats were compared using an unpaired Student's $t$-test.

\section{Materials}

Salts and all other drugs were obtained from Sigma Research Biochemicals (St Louis, MO) except where noted. $\mathrm{D}-\mathrm{APV}$ was dissolved in water and aliquots of $10 \mathrm{mM}$ stock solution were stored at $-20^{\circ} \mathrm{C}$.

\section{RESULTS}

Most studies on behavioral sensitization to psychostimulants are performed on adult rats, although there are reports that demonstrate young rats also show sensitized behavioral responses to amphetamine (McDougall et al, 1994; Duke et al, 1997). Prior to initiating physiological investigations of glutamatergic synapses, we wanted to confirm that the young rats used in our physiological experiments exhibit a sensitized response to amphetamine. Amphetamine or saline were administered to young rats for 5 consecutive days beginning at postnatal day 11. Rats administered amphetamine showed a progressively enhanced horizontal ambulatory locomotor response compared with salinetreated rats $(600 \pm 57$ counts on day 5 vs $165 \pm 37$ counts on day $1, n=10 ; p<0.00001$; Figure 1a). We monitored both ambulation and stereotypy (sniffing) in rats at different times after withdrawal. An amphetamine challenge

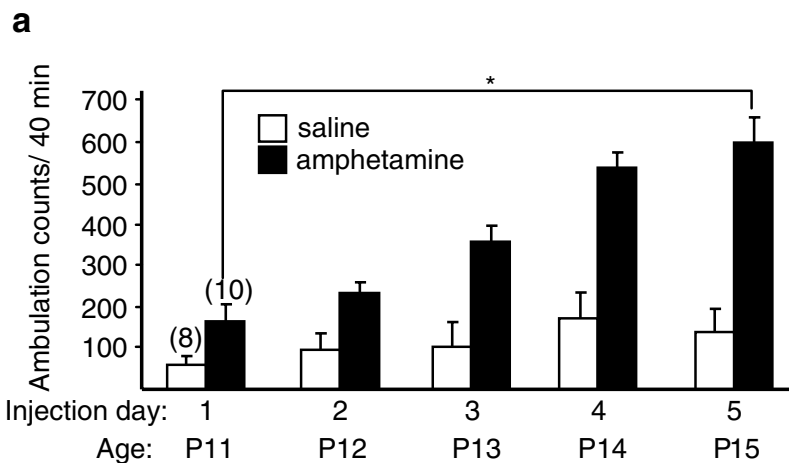

b
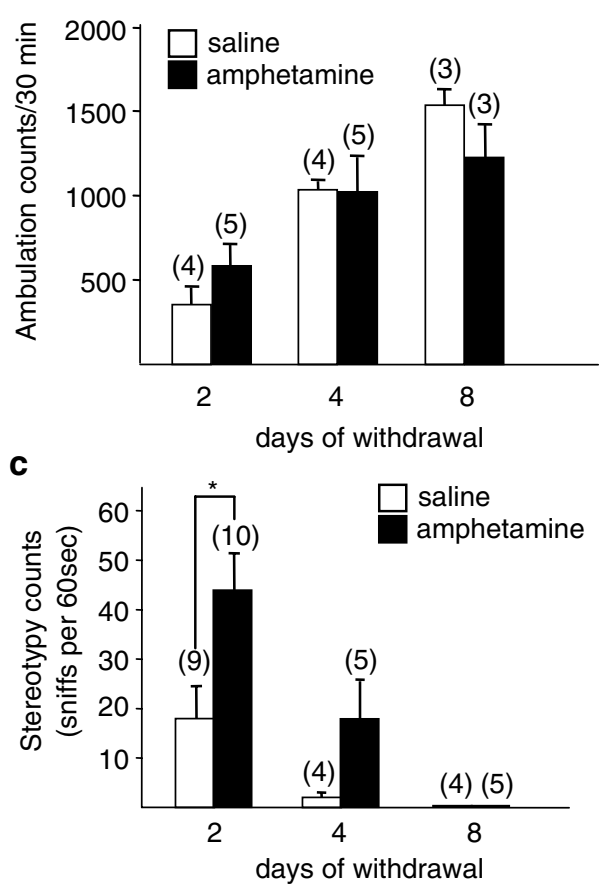

Figure I Young rats exhibit short-term behavioral sensitization. (a) Locomotor responses were monitored daily in young rats after the administration of either saline or amphetamine $(2.5 \mathrm{mg} / \mathrm{kg})$ for 5 consecutive days; ambulation responses were measured for $40 \mathrm{~min}$ following each injection. Rats administered amphetamine showed a progressive enhancement of horizontal ambulation with each dose of amphetamine. (b) Locomotor activity was monitored in response to an amphetamine challenge $(2.5 \mathrm{mg} / \mathrm{kg})$ on days 2,4 , or 8 following the 5 -day injection regimen. No significant difference in ambulation was observed between saline- or amphetamine-treated animals on any day. (c) Stereotypic sniffing behavior was monitored in response to an amphetamine challenge $(2.5 \mathrm{mg} / \mathrm{kg})$ presented 2,4 , or 8 days following a 5-day injection regimen of saline or amphetamine. Short-term sensitization of stereotypic sniffing was observed in rats previously exposed to amphetamine 2 days after withdrawal. This difference was not significant on withdrawal day 4 , and no stereotyped sniffing was observed on withdrawal day 8. 
$(2.5 \mathrm{mg} / \mathrm{kg})$ at 2,4 , or 8 days following withdrawal did not reveal any differences in ambulation between the amphetamine- and saline-treated rats (Figure 1b). However, amphetamine-treated rats manifested dramatic stereotypy 2 days after withdrawal $(44 \pm 7.5$ counts, amphetamine treated $(n=10)$ vs $18 \pm 6.5$ counts, saline treated $(n=9)$, Figure 1c). A difference in behavioral response to the amphetamine challenge was also observed on withdrawal day 4 , but was not statistically significant $(18 \pm 7.5$ counts, amphetamine treated $(n=4)$ vs $2 \pm 1$ counts, saline treated $(n=5) ; p=0.076$; Figure 1c); there was no stereotypic sniffing behavior 8 days after withdrawal. These data suggest that behavioral sensitization can be initiated in young rats, and that they can develop a short-lasting sensitization to repeated amphetamine treatment that may not be as persistent as sensitization in older animals.

We next asked whether young rats exhibit a sensitized behavioral response to an amphetamine challenge 1 day after a single amphetamine exposure. Either amphetamine or saline were administered and $24 \mathrm{~h}$ later this was followed with an amphetamine challenge. In response to the amphetamine challenge, ambulation was strongly enhanced $24 \mathrm{~h}$ after a first amphetamine treatment (1093 \pm 199 counts, $n=7$ vs $122 \pm 61$ counts, $n=5 ; p<0.005$; Figure $2 \mathrm{a})$. The overall locomotor activity observed in these animals was higher than that observed in our 5-day experiment, a difference we attribute to the different age of the animals.

We next examined the effect of a single dose of amphetamine on the AMPAR/NMDAR ratio of glutamatergic synapses on VTA DA cells in the same animals monitored for locomotor activity. We first tested slices prepared $24 \mathrm{~h}$ after administering a single dose of amphetamine or saline. During whole-cell voltage-clamp recordings from DA neurons held at $+40 \mathrm{mV}$, EPSCs were composed of both AMPA- and NMDA-receptor-mediated currents. D-APV $(50 \mu \mathrm{M})$ was then added to the bath to isolate the AMPAR component (Figure 2b). We found a robust increase in AMPAR/NMDAR ratios in slices from animals administered a single dose of amphetamine $(0.67 \pm 0.074, n=5)$ compared to saline controls $(0.40 \pm 0.052, n=6 ; p<0.05$; Figure 2c). These data are consistent with the idea that behavioral sensitization to
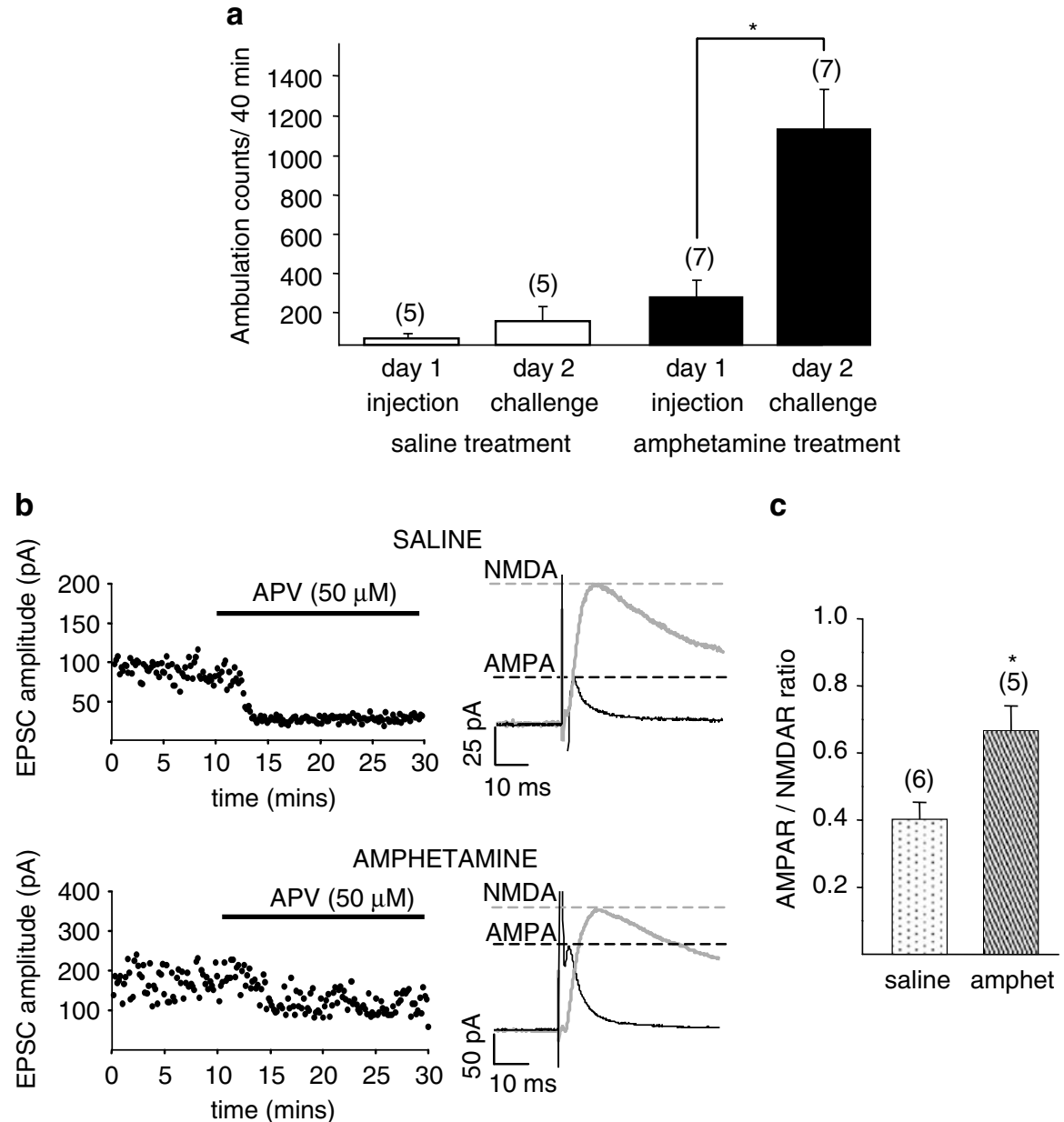

Figure 2 Behavioral sensitization to a single dose of amphetamine is correlated with increased AMPAR/NMDAR ratios. (a) Rats aged PI5 were administered either amphetamine $(2.5 \mathrm{mg} / \mathrm{kg})$ or saline and were challenged with an amphetamine $(2.5 \mathrm{mg} / \mathrm{kg})$ injection $24 \mathrm{~h}$ later. Rats that were previously administered amphetamine had a greater ambulation response measured for $40 \mathrm{~min}$ after an amphetamine challenge than did the saline controls. (b) Responses of individual DA cells to synaptic stimulation in the absence and presence of the NMDA receptor antagonist, D-APV (50 $\mu M$ ). Recordings were made from brain slices prepared from rats injected with saline (top panel) vs amphetamine (bottom panel) 24-h after their first injection. Averages of 25 AMPA and NMDA EPSCs are shown to the right of each graph. (c) Averaged AMPAR/NMDAR ratios from DA cells in slices from saline- vs amphetamineinjected animals. 
amphetamine is correlated with an increased AMPAR/ NMDAR ratio.

An increase in synaptic levels of GluR1 could account for the observed increase in the AMPAR/NMDAR ratios. Moreover, it has been shown that overexpression of GluR1 by itself produces behavioral sensitization (Carlezon et al, 1997), suggesting that increases in synaptic GluR1 could explain our findings. One possible consequence of a large increase in GluR1 is the synaptic insertion of homomeric AMPA receptors lacking GluR2. AMPARs lacking GluR2 are significantly more permeable to $\mathrm{Ca}^{2+}$ than AMPA receptors containing GluR2, and also exhibit an inwardly rectifying current-voltage (I-V) relationship (Verdoorn et al, 1991; Hollmann et al, 1991; PellegriniGiampietro, 2003). It has been hypothesized that an increase in $\mathrm{Ca}^{2+}$-permeable AMPA receptors at VTA synapses after exposure to drugs of abuse might cause significant changes in synaptic function, a possible early abnormality in the system associated with the development of addiction (Carlezon and Nestler, 2002). We therefore tested whether we could observe the characteristic inwardly rectifying $I-V$ relationship at AMPAR synapses of VTA DA neurons. If GluR1 homomers made up a significant proportion of synaptic AMPA receptors, we would expect to observe a rectifying $I-V$ curve. Instead, we found that $I-V$ curves of AMPAR EPSCs from DA cells from saline or amphetamine-treated animals were linear. Furthermore, there was no apparent difference between $I-V$ curves recorded in neurons from animals pretreated with amphetamine or saline (Figure 3). These data indicate that if the increase in AMPAR/NMDAR ratios results from insertion of AMPARs, these newly inserted AMPARs are not GluR1 homomers.

The increase in the AMPAR/NMDAR ratio seen after amphetamine exposure suggests that there may be an increase in AMPA receptors at the synapse, an increase in AMPA receptor function, and/or a decrease in NMDA receptor number or function. In the hippocampus, LTP is dependent on increased insertion of the AMPA receptor subunit, GluR1 (Shi et al, 1999; Zamanillo et al, 1999). Previous studies found no detectable changes in the VTA in total cellular protein levels of GluR1 between cocaine- and

a
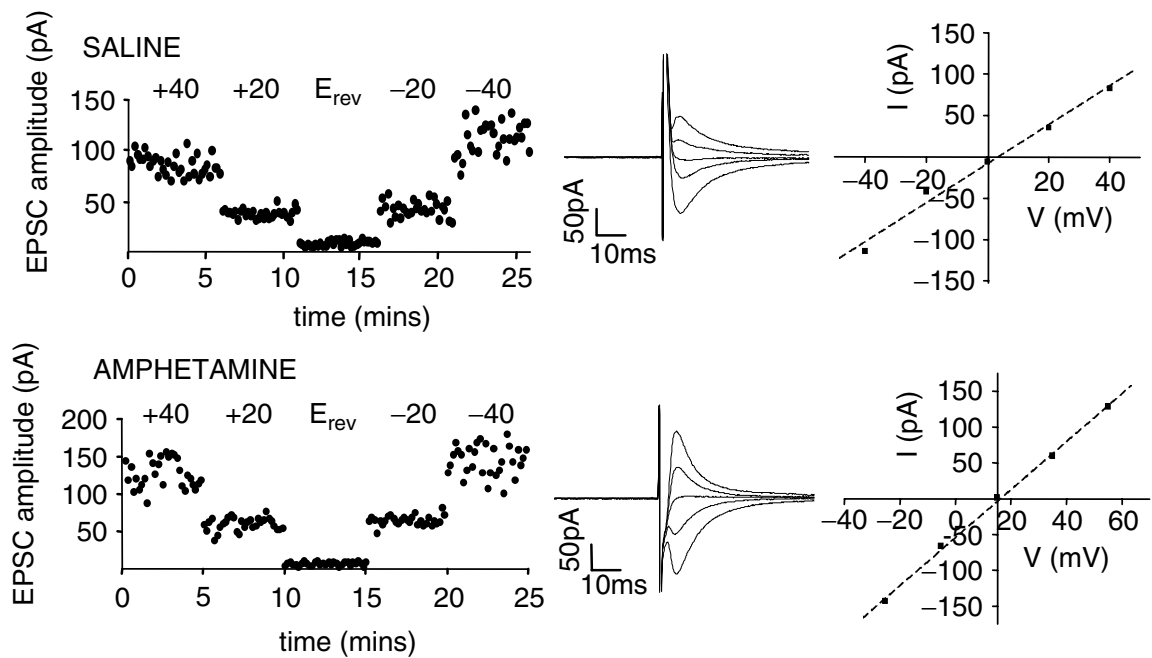

b
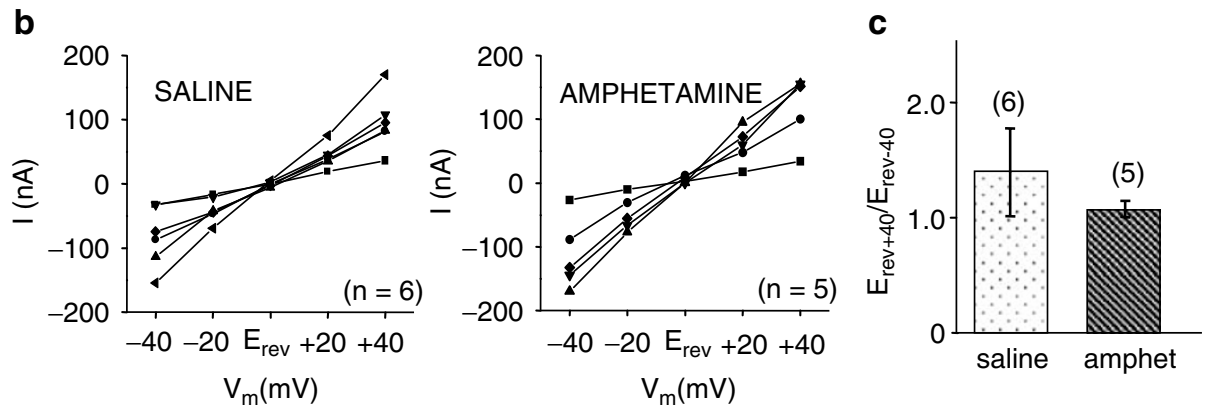

Figure 3 Current-voltage $(I-V)$ relationships for DA cells from saline- and amphetamine-treated rats do not show inward rectification. Rats were given either saline or amphetamine $(2.5 \mathrm{mg} / \mathrm{kg}) 24 \mathrm{~h}$ prior to the preparation of brain slices. Recordings were made from DA neurons perfused with ACSF + picrotoxin + D-APV. (a) Left panel: Individual experiments showing AMPAR EPSC amplitudes at voltages \pm 20 and $\pm 40 \mathrm{mV}$ from the reversal potential $\left(E_{\text {rev }}\right)$ recorded from DA neurons in slices from saline- and amphetamine-treated rats. Middle panel: Averaged AMPAR EPSCs from these experiments recorded at \pm 20 and $\pm 40 \mathrm{mV}$ from the reversal potential and at the reversal potential (each trace represents the average of 24 EPSCs recorded over $4 \mathrm{~min}$ ). Right panel: Plots of the $I-V$ relationships for these experiments. (b) Individual $I-V$ curves recorded in six DA neurons from salinetreated rats (left panel) and five DA neurons from amphetamine-treated rats (right panel). Each symbol represents the averaged EPSC at each potential for a single DA neuron as illustrated in (a). (c) $E_{\text {rev }+40} / E_{\text {rev }-40}$ EPSC amplitude ratios for DA neurons from saline- and amphetamine-treated rats are not significantly different. 
saline-treated mice (Ungless et al, 2001). However, because hippocampal LTP is dependent on the insertion of GluR1 into the postsynaptic membrane at synapses (Shi et al, 1999) rather than a simple increase in total cellular GluR1 levels, we reasoned that increases in AMPA receptor number at the surface might not be reflected in total cellular protein levels but only in surface receptor expression. Therefore, we examined surface expression of AMPA and NMDA receptors on VTA neurons from rats that had received a single dose of either saline or amphetamine $24 \mathrm{~h}$ earlier. Biotinylated surface proteins were separated from unlabeled intracellular proteins by affinity purification and we compared the ratio of surface to total protein of the GluR1 subunit of the AMPA receptor and the NR1 subunit of the NMDA receptor using Western blot analysis. Even using this approach, however, we could not detect significant differences in surface levels of GluR1 when comparing amphetamine- and saline-treated animals (Figure 4). In addition, there were no changes observed in NR1 or transferrin surface expression as a result of amphetamine exposure.

We and others have observed changes in the behavior of glutamatergic synapses in the VTA $24 \mathrm{~h}$ after exposure to
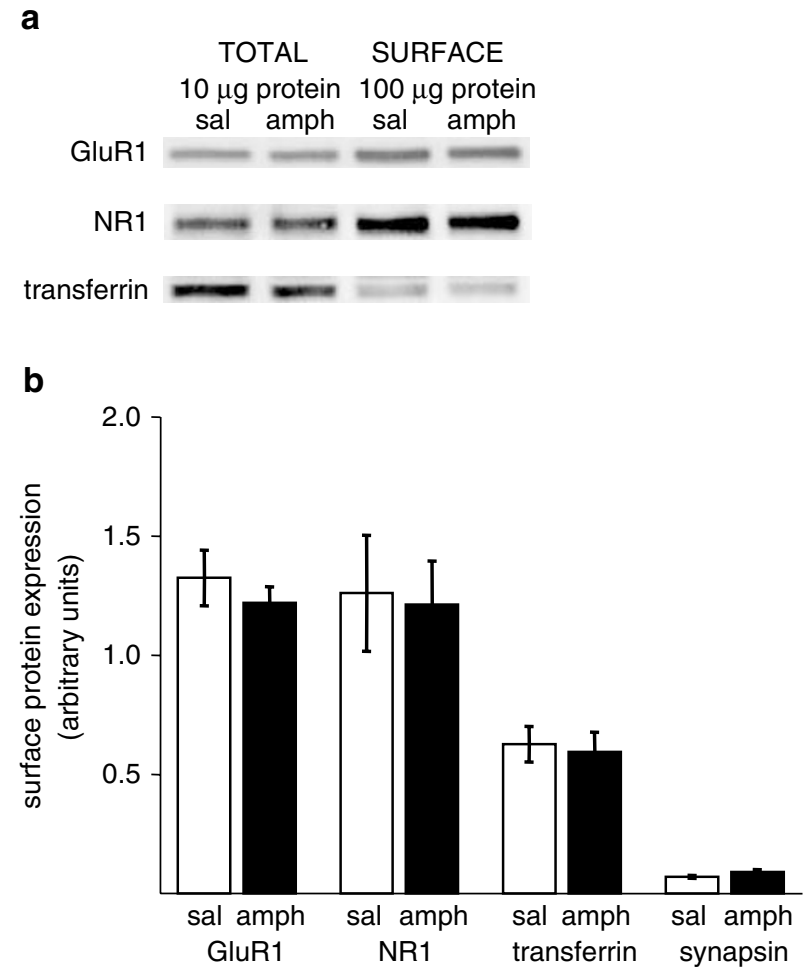

Figure 4 Surface expression of both GluRI and NRI is unchanged $24 \mathrm{~h}$ after exposure to amphetamine. (a) A sample Western blot of VTA slices from saline- (sal) and amphetamine- (amph) treated rats showing the total protein levels and surface levels of GluRI, NRI, and transferrin. Ten times as much protein was loaded into the 'surface' lanes as in the 'total' lanes. (b) Comparison of surface expression of GluRI, NRI, and transferrin reveals no difference in surface expression as a result of amphetamine exposure. For each sample from saline- and amphetamine-treated rats $(n=3$ animals in each group), the level of biotinylated surface protein expression was normalized to total protein levels. The amount of biotinylation of the intracellular protein, synapsin, was $0.07 \pm 0.006$ (saline) and $0.09 \pm 0.01$ (amphetamine) of total protein. amphetamine (Saal et al, 2003). We wanted to know whether the changes in AMPAR/NMDAR ratios are a consequence of a $24 \mathrm{~h}$-long cascade of events or whether they represent a relatively rapid response to amphetamine, similar to hippocampal LTP, which can develop within minutes. Amphetamine becomes available in the brain within minutes following an i.p. injection (Riffee and Wilcox, 1985) and, therefore, we chose a time point of $2 \mathrm{~h}$ after amphetamine injection to test for changes in the AMPAR/NMDAR ratio. At $2 \mathrm{~h}$ following amphetamine injections, we prepared acute slices from those animals with a locomotor response greater than 120 ambulation counts/hour, (Figure 5a). Surprisingly, as early as $2 \mathrm{~h}$ after amphetamine injection, the AMPAR/NMDAR ratios were significantly increased in DA cells from animals administered a single dose of amphetamine $(0.69 \pm 0.095, n=9)$ compared to saline controls $(0.38 \pm 0.044, n=6 ; p<0.05)$ (Figure 5b).

Although in vivo studies indicate that the VTA is both necessary and sufficient to initiate behavioral sensitization (Vezina, 1993), this may require intact circuitry between the VTA and other components of the reward system. To further dissect the mechanism of amphetamine-induced increases in AMPAR/NMDAR ratio, it would be convenient to be able to reproduce such changes in vitro. We therefore asked whether in vitro exposure of VTA slices to amphetamine for $2 \mathrm{~h}$ could induce the changes in AMPAR/NMDAR ratios observed in vivo. We found, however, that there was no difference in the AMPAR/ NMDAR ratio after $2 \mathrm{~h}$ of exposure to bath-applied amphetamine (Figure $5 \mathrm{c} ; 0.46 \pm 0.048$ saline $(n=17)$ vs $0.60 \pm 0.079$ amphetamine $(n=14) ; p=0.12)$. These data indicate that normal synaptic transmission, which is absent in the deafferented slice preparation, and/or an intact circuit between the VTA and other brain regions is required for the change in AMPAR/NMDAR ratio.

\section{DISCUSSION}

\section{Young Rats Exhibit Short-Term Sensitization to Repeated Amphetamine Injections}

Most studies of behavioral sensitization to psychostimulants are performed on adult rats, which show robust, progressive augmentation of locomotor activity with repeated drug administration, and persistent sensitization that can last up to a year (Robinson and Berridge, 1993). In order to facilitate successful visualized patch-clamp recordings, we typically use young rats (p15-19) and, therefore, we wanted to be certain that these animals would also show sensitization. As previously reported (McDougall et al, 1994), we found that young rats administered amphetamine for 5 consecutive days showed a progressive enhancement in their ambulation counts when compared with rats that received saline. We also observed enhanced stereotypy to amphetamine challenge in amphetamine-treated rats at 2 and 4 days after withdrawal that was no longer apparent at 8 days after withdrawal. The preservation of sensitization of stereotypy under conditions during which locomotor sensitization is not observed may reflect differences in the extent of neuroadaptations in the dopaminergic circuits that mediate stereotypy (ventrolateral striatum) and ambulation 


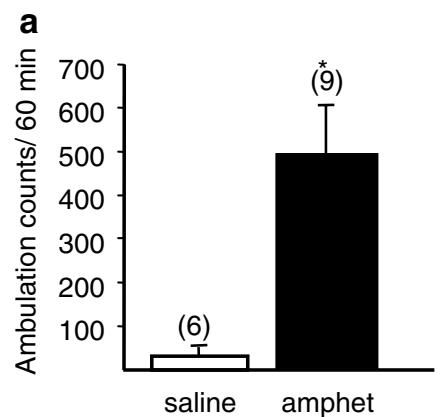

b 2 hours amphetamine in vivo

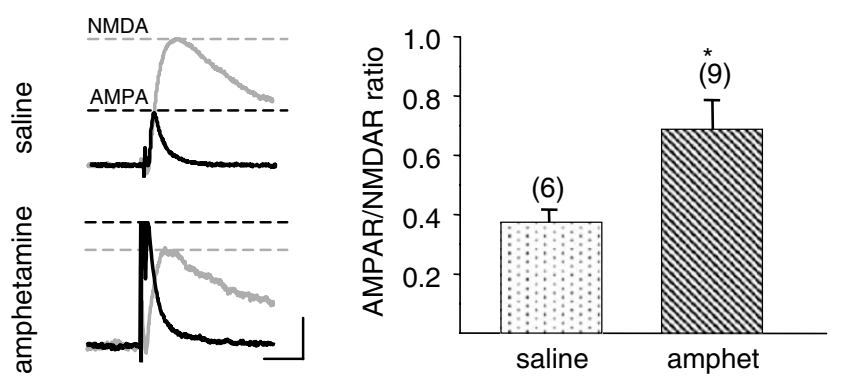

C 2 hours amphetamine in vitro
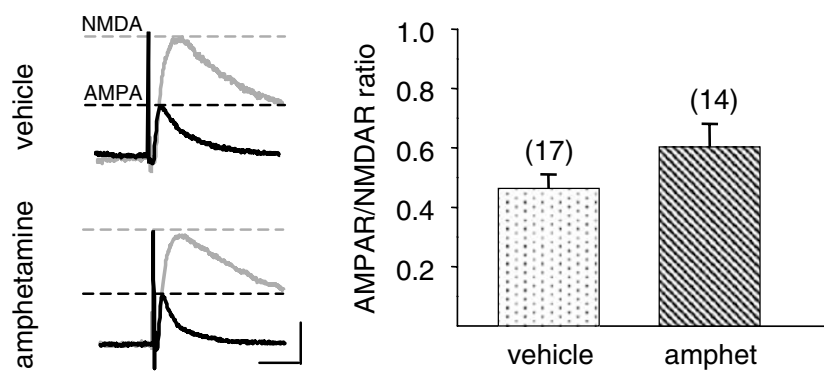

Figure 5 A 2-h in vivo exposure to amphetamine is sufficient to increase the AMPAR/NMDAR ratio. (a) Locomotor responses of rats (PI5-PI8) were measured for $60 \mathrm{~min}$ after an injection of saline $(31 \pm 21$ counts, $n=6)$ or amphetamine $(2.5 \mathrm{mg} / \mathrm{kg} ; 494 \pm 112, n=9 ; p<0.02)$. These animals were then used for physiological experiments in (b). (b) Left panel: Examples of AMPAR- (black) and NMDAR-mediated (gray) EPSCs from individual DA cells in slices from saline- (top panel) vs amphetamine(bottom panel) treated animals. Calibration: 20 pA, 10 ms. Right panel: Averaged AMPAR/NMDAR ratios in DA cells from saline- and amphetamine-treated animals. (C) Left panel: Examples of AMPAR and NMDAR EPSCs from individual DA cells in slices exposed for $2 \mathrm{~h}$ to either vehicle (top panel) or amphetamine (bottom panel). Calibration: $20 \mathrm{pA}$, 10 ms. Right panel: Averaged AMPAR/NMDAR ratios in DA cells from VTA slices exposed to either vehicle or bath-applied amphetamine $(\mathrm{I} \mu \mathrm{M})$.

(NAcc) as a result of chronic amphetamine exposure. Such changes may promote stereotypy to the extent that ambulation is reduced (Segal and Schuckit, 1983). The consistent conclusion is that young rats do exhibit sensitization, but its duration is briefer than in adults. The neuroadaptations that result from amphetamine exposure may be less permanent in young rats as the brain is in a more plastic state at young ages. Since sensitization is initiated in young and adult rats, it remains valid to examine the mechanisms underlying the onset of sensitization in younger animals.

A Single Dose of Amphetamine Alters Glutamatergic Synapses in the VTA

We found that a single dose of amphetamine was sufficient to produce enhanced ambulation to an amphetamine challenge $24 \mathrm{~h}$ later. This result is consistent with those previously reported in response to cocaine and amphetamine (Vanderschuren et al, 1999; Ungless et al, 2001; Saal et al, 2003). The same dose of amphetamine was also sufficient to increase the AMPAR/NMDAR ratios at the glutamatergic synapses in the VTA $24 \mathrm{~h}$ later. Our observations are consistent with those reported recently for amphetamine and several other drugs of abuse (Ungless et al, 2001; Saal et al, 2003). In the hippocampus, an increase in the AMPAR component of the excitatory postsynaptic response occurs at synapses that have undergone LTP (Kauer et al, 1988; Isaac et al, 1995; Liao et al, 1995; Malinow and Malenka, 2002). By extension, the increased AMPAR/NMDAR ratios in the VTA suggest that excitatory VTA synapses in animals exposed to drugs of abuse are potentiated $24 \mathrm{~h}$ later. Ungless et al (2001) have demonstrated that further LTP could not be induced at synapses onto DA cells in VTA slices prepared from cocaine-treated animals, suggesting that these synapses are already maximally potentiated. Furthermore, the fact that we and others can detect these changes in randomly selected DA neurons indicates that the majority of excitatory synapses on DA neurons in the VTA must be potentiated after amphetamine.

What could account for an increase in the AMPAR/ NMDAR ratio? Based on extensive studies of LTP in the hippocampus, one reasonable suggestion is that exposure to amphetamine or other drugs of abuse increases AMPA receptor expression at the synapse. Total protein levels of the GluR1 subunit of the AMPA receptor were previously reported to be unchanged $24 \mathrm{~h}$ after cocaine administration (Ungless et al, 2001). Here, we also found no detectable changes in surface expression levels of either the GluR1 subunit of the AMPA receptor or the NR1 subunit of the NMDA receptor in amphetaminetreated animals. We and others have previously used this technique to look at GluR1 and NR1 subunits in slice preparations after LTP or LTD induction (Heynen et al, 2000; Gutlerner et al, 2002). In both cases, significant changes in surface protein levels were observed. In VTA slices, for example, application of a cAMP analogue induces LTD at synapses on DA cells and is accompanied by a significant decrease in GluR1 surface expression (Gutlerner et al, 2002). Perhaps in these instances, plasticity is more robust or widespread. Alternatively, the increase in observed AMPAR current may reflect enhanced function of pre-existing AMPA receptors, or the preferential increase in synaptic levels of AMPARs composed of subunits other than GluR1. However, while our experiments did not detect differences in overall GluR1 surface levels, we cannot rule out increases in GluR1 expression at excitatory VTA synapses. The presence of other, unpotentiated glutamate synapses (on GABAergic neurons, for example), extrasynaptic glutamate receptors, and receptors on glial cells may confound our ability to detect the relevant increases in GluR1 levels using biotinylation of surface proteins. 


\section{AMPA Receptors at Excitatory VTA Synapses do not Appear to Lack GluR2}

It has been hypothesized that one consequence of drug exposure in the VTA is an increase of GluR1 at the synapse sufficient to promote the formation of homomeric GluR1 AMPA receptors (Carlezon and Nestler, 2002). We assessed the rectification of synaptic AMPA receptor current-voltage curves because GluR1 homomeric receptors exhibit inward rectification. Our data show little or no rectification of AMPA receptor currents either before or after amphetamine exposure. These data strongly support the idea that AMPA receptors at a majority of the glutamatergic synapses on DA cells contain the GluR2 subunit before and after exposure to amphetamine. Our observations therefore suggest that after a single dose of amphetamine, the AMPA receptors at VTA synapses are not expected to be significantly $\mathrm{Ca}^{2+}$ permeable. The simplest interpretation of these results is that the AMPA receptors at VTA synapses contain both GluR2 and GluR1 subunits even during the enhanced insertion postulated to occur after amphetamine exposure. Viral overexpression of GluR1 in the VTA, by strongly increasing the proportion of this subunit, is very likely to produce synapses with $\mathrm{Ca}^{2+}$-permeable AMPARs, which may indeed contribute to the development of sensitization and other downstream behavioral changes (Carlezon et al, 1997).

\section{Changes in AMPAR/NMDAR Ratio are Rapid}

The increase in AMPAR/NMDAR ratio in response to amphetamine is detectable after $24 \mathrm{~h}$; at this time point, multiple molecular and cellular cascades could have been initiated. However, LTP induced by afferent stimulation has a rapid onset (Bonci and Malenka, 1999; Overton et al, 1999; Mansvelder and McGehee, 2000). If the increase in AMPAR/ NMDAR ratio is the result of LTP induction, we predicted that the increase in synaptic transmission in response to drug administration would occur within hours rather than days. In support of this prediction, an increased AMPAR/ NMDAR ratio is observable within $2 \mathrm{~h}$ of an i.p. injection, and thus within an even shorter period after amphetamine reaches the brain. This observation is significant because it indicates that potentiation of the glutamatergic synapses onto DA neurons may be an early neuroadaptation in the VTA caused by drugs of abuse.

\section{How does Amphetamine Initiate LTP at VTA Synapses?}

The observed increase in AMPAR/NMDAR ratios at glutamatergic synapses in the VTA following amphetamine exposure suggests that LTP has occurred. One possible mechanism by which amphetamine may elicit LTP is by removing constitutive processes that prevent potentiation. For example, studies by our group and others have found that amphetamine entirely blocks longterm depression at excitatory synapses on VTA neurons via activation of D2 receptors on DA neurons (Jones et al, 2000; Thomas et al, 2000). Amphetamine also blocks the mGluR-mediated hyperpolarization of DA neurons (Paladini et al, 2001), an independent action that would promote increased DA neuron excitability. We hypothe- size that the block of LTD- and mGluR-mediated hyperpolarization by amphetamine will promote LTP by removing normal brakes on excitatory synapses, although this remains to be proven.

Nonvesicular glutamate may be another potential source of glutamate that could contribute to potentiation. Psychostimulants promote glutamate efflux in the VTA (Kalivas and Duffy, 1995; Xue et al, 1996; Wolf and Xue, 1998), due to efflux from glutamate transporters and cystine-glutamate exchangers (Wolf and Xue 1999; Baker et al, 2002, 2003). In principle, this rise in extracellular glutamate could contribute to the development of LTP, but studies indicate that this rise does not begin until $2 \mathrm{~h}$ after psychostimulant exposure (Xue et al, 1996; Wolf and Xue, 1998). Since we observe increased AMPAR/NMDAR ratios within this time period, the rise in extracellular glutamate may not be required for these early synaptic changes.

Lastly, there is evidence to support a role for NMDA receptor activation in the potentiation of glutamatergic synapses. Ungless et al (2001) have shown that the potentiation at glutamatergic synapses by cocaine is NMDA receptor dependent, and NMDA receptor activation is also required in the in vitro induction of LTP (Bonci and Malenka, 1999). However, the precise cellular mechanisms by which drugs of abuse induce LTP at VTA synapses still remain to be discovered.

\section{In Vitro Exposure to Amphetamine does not Trigger LTP}

In other systems, LTP induction is critically dependent on action potential-dependent electrical activity in glutamatergic afferents, which results in glutamate release and subsequent glutamate receptor activation. While we observed potentiation when amphetamine was administered in vivo, we were unable to reproduce the increase in AMPAR/NMDAR ratios in VTA slices exposed to amphetamine in vitro (although we did observe a trend, $p=0.12$ ). This was consistent with our previous work showing that amphetamine does not increase glutamatergic synaptic transmission in vitro, and even causes synaptic depression at high concentrations (Jones and Kauer, 1999). We believe that these results are a consequence of using the brain slice preparation, in which the majority of glutamatergic cell bodies that innervate DA cells are missing, so that too little endogenous activity remains at excitatory synapses to initiate potentiation. We cannot rule out that the intact brain is required for potentiation. However, previous work demonstrated that local injection of amphetamine into the VTA in vivo is sufficient to trigger sensitization (Vezina, 1993; Cador et al, 1995). We therefore speculate that amphetamine can directly trigger LTP within the VTA in vivo because sufficient levels of glutamatergic synaptic activity are present, but that in our slice experiments levels of synaptic activity are too low to trigger LTP.

\section{CONCLUSIONS}

Our experiments demonstrate that a single exposure to amphetamine in vivo is sufficient to potentiate excitatory synapses onto VTA DA neurons within $2 \mathrm{~h}$. We do not find 
evidence of GluR1 homomeric AMPARs at VTA synapses after amphetamine, nor could we detect an increase in surface levels of GluR1 in $24 \mathrm{~h}$ after amphetamine with the methods used here, when the AMPAR/NMDAR ratio is increased nearly 2 -fold. Although these data cannot rule out the hypothesis that GluR1 insertion at synapses is responsible for the synaptic potentiation observed after amphetamine treatment, our findings suggest that it will be important to understand more about the cellular processes that underlie LTP at these synapses, as they may differ from those reported in other brain regions.

\section{ACKNOWLEDGEMENTS}

We thank Drs M Bear, BJ Yoon, J Whitlock, J Marshall, L Needleman, N Riley, Z Ren, A Zhitkovich, M Reynolds, and $\mathrm{L}$ Gabel for providing reagents, equipment, and technical expertise, and Drs J Edwards, E Penick, and F Salmanzadeh for helpful comments on the manuscript. This work was supported by grants from NARSAD and NIH DA11289 to JAK, DA15588 to LJF.

\section{REFERENCES}

Baker DA, McFarland K, Lake RW, Shen H, Tang XC, Toda S et al (2003). Neuroadaptations in cystine-glutamate exchange underlie cocaine relapse. Nat Neurosci 6: 743 .

Baker DA, Xi ZX, Shen H, Swanson CJ, Kalivas PW (2002). The origin and neuronal function of in vivo nonsynaptic glutamate. J Neurosci 22: 9134.

Beckstead RM (1979). An autoradiographic examination of corticocortical and subcortical projections of the mediodorsalprojection (prefrontal) cortex in the rat. J Comp Neurol 184: 43-62.

Bjijou Y, Stinus L, Moal ML, Cador M (1996). Evidence for selective involvement of dopamine D1 receptors of the ventral tegmental area in the behavioral sensitization induced by intra-ventral tegmental area injections of D-amphetamine. J Pharmacol Exp Ther 277: 1177-1187.

Bonci A, Malenka RC (1999). Properties and plasticity of excitatory synapses on dopaminergic and GABAergic cells in the ventral tegmental area. J Neurosci 19: 3723-3730.

Cador M, Bjijou Y, Cailhol S, Stinus L (1999). D-amphetamineinduced behavioral sensitization: implication of a glutamatergic medial prefrontal cortex-ventral tegmental area innervation. Neuroscience 94: 705-721.

Cador M, Bjijou Y, Stinus L (1995). Evidence of a complete independence of the neurobiological substrates for the induction and expression of behavioral sensitization to amphetamine. Neuroscience 65: 385-395.

Carlezon Jr WA, Boundy VA, Haile CN, Lane SB, Kalb RG, Neve $\mathrm{RL}$ et al (1997). Sensitization to morphine induced by viralmediated gene transfer. Science 277: 812-814.

Carlezon Jr WA, Nestler EJ (2002). Elevated levels of GluR1 in the midbrain: a trigger for sensitization to drugs of abuse? Trends Neurosci 25: 610-615.

Carr DB, Sesack SR (1996). Hippocampal afferents to the rat prefrontal cortex: synaptic targets and relation to dopamine terminals. J Comp Neurol 369: 1-15.

Christie MJ, Bridge S, James LB, Beart PM (1985). Excitotoxic lesions suggest an aspartatergic projection from rat medial prefrontal cortex to ventral tegmental area. Brain Res 333 169-172.

Di Chiara G, Imperato A (1988). Drugs abused by humans preferentially increase synaptic dopamine concentrations in the mesolimbic system of freely moving rats. Proc Natl Acad Sci 85: 5274-5278.

Druhan JP, Deschamps SE, Stewart J (1993). D-amphetamine-like stimulus properties are produced by morphine injections into the ventral tegmental area but not into the nucleus accumbens. Behav Brain Res 59: 41-51.

Duke MA, O’Neal J, McDougall SA (1997). Ontogeny of dopamine agonist-induced sensitization: role of NMDA receptors. Psychopharmacology (Berl) 129: 153-160.

Gutlerner JL, Penick EC, Snyder EM, Kauer JA (2002). Novel protein kinase A-dependent long-term depression of excitatory synapses. Neuron 36: 921-931.

Heynen AJ, Quinlan EM, Bae DC, Bear MF (2000). Bidirectional, activity-dependent regulation of glutamate receptors in the adult hippocampus in vivo. Neuron 28: 527-536.

Hollmann M, Hartley M, Heinemann S (1991). $\mathrm{Ca}^{2+}$ permeability of KA-AMPA - gated glutamate receptor channels depends on subunit composition. Science 252: 851-853.

Hyman SE, Malenka RC (2001). Addiction and the brain: the neurobiology of compulsion and its persistence. Nat Rev Neurosci 2: 695-703.

Isaac JTR, Nicoll RA, Malenka RC (1995). Evidence for silent synapses: implications for the expression of LTP. Neuron 15: 427-434.

Jones S, Kauer JA (1999). Amphetamine depresses excitatory synaptic transmission via serotonin receptors in the ventral tegmental area. J. Neurosci 19: 9780-9787.

Jones S, Kornblum JL, Kauer JA (2000). Amphetamine blocks longterm synaptic depression in the ventral tegmental area. $J$ Neurosci 20: 5575-5580.

Kalivas PW, Alesdatter JE (1993). Involvement of NMDA receptor stimulation in the ventral tegmental area and amygdala in behavioral sensitization to cocaine. J Pharmacol Exp Ther 267: 486-495.

Kalivas PW, Duffy P (1987). Sensitization to repeated morphine injection in the rat: possible involvement of A10 dopamine neurons. J Pharmacol Exp Ther 241: 204-212.

Kalivas PW, Duffy P (1995). D1 receptors modulate glutamate transmission in the ventral tegmental area. J Neurosci 15: 5379-5388.

Kalivas PW, Weber B (1988). Amphetamine injection into the ventral mesencephalon sensitizes rats to peripheral amphetamine and cocaine. J Pharmacol Exp Ther 245: 1095-1101.

Kauer JA (2004). Learning mechanisms in addiction: synaptic plasticity in the ventral tegmental area as a result of exposure to drugs of abuse. Annu Rev Physiol 66: 447-475.

Kauer JA, Malenka RC, Nicoll RA (1988). A persistent postsynaptic modification mediates long-term potentiation in the hippocampus. Neuron 1: 911-917.

Kim JH, Vezina P (1998). Metabotropic glutamate receptors are necessary for sensitization by amphetamine. Neuroreport 9: 403-406.

Koob GF (1992). Drugs of abuse: anatomy, pharmacology, and function of reward pathways. TiPS 13: 177-184.

Liao D, Hessler NA, Malinow R (1995). Activation of postsynaptically silent synapses during pairing-induced LTP in CA1 region of hippocampal slice. Nature 375: 400-404.

Malinow R, Malenka RC (2002). AMPA receptor trafficking and synaptic plasticity. Ann Rev Neurosci 25: 103-126.

Mansvelder HD, McGehee DS (2000). Long-term potentiation of excitatory inputs to brain reward areas by nicotine. Neuron 27: 349-357.

McDougall SA, Duke MA, Bolanos CA, Crawford CA (1994). Ontogeny of behavioral sensitization in the rat: effects of direct and indirect dopamine agonists. Psychopharmacology 116: 483-490.

Nestler EJ (1992). Molecular mechanisms of drug addiction. J Neurosci 12: 2439-2450. 
Oades RD, Halliday GM (1987). Ventral tegmental (A10) system: neurobiology. 1. Anatomy and connectivity. Brain Res 434: $117-165$.

Overton PG, Richards CD, Berry MS, Clark D (1999). Long-term potentiation at excitatory amino acid synapses on midbrain dopamine neurons. Neuroreport 10: 221-226.

Paladini CA, Fiorillo CD, Morikawa H, Williams JT (2001). Amphetamine selectively blocks inhibitory glutamate transmission in dopamine neurons. Nat Neurosci 4: 275-281.

Paxinos G, Watson C (1986). The Rat Brain in Stereotaxic Coordinates. Academic Press: San Diego, CA.

Pellegrini-Giampietro DE (2003). An activity-dependent sperminemediated mechanism that modulates glutamate transmission. Trends Neurosci 26: 9-11.

Riffee WH, Wilcox RE (1985). Effects of multiple pretreatment with apomorphine and amphetamine on amphetamine-induced locomotor activity and its inhibition by apomorphine. Psychopharmacology 85: 97-101.

Robinson TE, Berridge KC (1993). The neural basis of drug craving: an incentive-sensitization theory of addiction. Brain Res Rev 18: 247-291.

Saal D, Dong Y, Bonci A, Malenka RC (2003). Drugs of abuse and stress trigger a common synaptic adaptation in dopamine neurons. Neuron 37: 577-582.

Schenk S, Snow S (1994). Sensitization to cocaine's motor activating properties produced by electrical kindling of the medial prefrontal cortex but not of the hippocampus. Brain Res 659: 17-22.

Segal DS, Schuckit MA (1983). Animal models of stimulantinduced psychosis. In: Creese I (ed). Stimulants: Neurochemical, Behavioral, and Clinical Perspectives. Raven Press: New York. pp 131-177.

Self DW, Nestler EJ (1998). Relapse to drug-seeking: neural and molecular mechanisms. Drug Alcohol Depend 51: 49-60.

Shi SH, Hayashi Y, Petralia RS, Zaman SH, Wenthold RJ, Svoboda $\mathrm{K}$ et al (1999). Rapid spine delivery and redistribution of AMPA receptors after synaptic NMDA receptor activation. Science 284: 1811-1816.

Thomas MT, Malenka RC, Bonci A (2000). Modulation of long-term depression by dopamine in the mesolimbic system. J Neurosci 20: 5581-5586.
Ungless MA, Whistler JL, Malenka RC, Bonci A. (2001). Single cocaine exposure in vivo induces long-term potentiation in dopamine neurons. Nature 411: 583-587.

Vanderschuren LJ, Schmidt ED, De Vries TJ, Van Moorsel CA, Tilders FJ, Schoffelmeer AN (1999). A single exposure to amphetamine is sufficient to induce long-term behavioral, neuroendocrine, and neurochemical sensitization in rats. J Neurosci 19: 9579-9586.

Verdoorn TA, Burnashev N, Monyer H, Seeburg PH, Sakmann B (1991). Structural determinants of ion flow through recombinant glutamate receptor channels. Science 252: 1715-1718.

Vezina P (1993). Amphetamine injected into the ventral tegmental area sensitizes the nucleus accumbens dopaminergic response to systemic amphetamine: an in vivo microdialysis study in the rat. Brain Res 605: 332-337.

Vezina P, Queen AL (2000). Induction of locomotor sensitization by amphetamine requires the activation of NMDA receptors in the rat ventral tegmental area. Psychopharmacology 151: 184-191.

Vezina P, Stewart J (1989). The effect of dopamine receptor blockade on the development of sensitization to the locomotor activating effects of amphetamine and morphine. Brain Res 499: 108-120.

White FJ (1996). Synaptic regulation of mesocorticolimbic dopamine neurons. Ann Rev Neurosci 16: 405-436.

Wolf ME, Xue C-J (1998). Amphetamine and D1 dopamine receptor agonists produce biphasic effects on glutamate efflux in rat ventral tegmental area: modification by repeated amphetamine administration. J Neurochem 70: 198-209.

Wolf ME, Xue CJ (1999). Amphetamine-induced glutamate efflux in the rat ventral tegmental area is prevented by MK-801, SCH 23390, and ibotenic acid lesions of the prefrontal cortex. J Neurochem 73: 1529-1538.

Xue C-J, Ng JP, Li Y, Wolf ME (1996). Acute and repeated systemic amphetamine administration: Effects on extracellular glutamate, aspartate, and serine levels in rat ventral tegmental area and nucleus accumbens. J Neurochem 67: 352-363.

Zamanillo D, Sprengel R, Hvalby O, Jensen V, Burnashev N, Rozov A et al (1999). Importance of AMPA receptors for hippocampal synaptic plasticity but not for spatial learning. Science 284: 1805-1811. 